УДК 547.327

ИНГИБИТОРЫ КИСЛОТНОЙ КОРРОЗИИ В ХИМИЧЕСКОЙ ТЕХНОЛОГИИ ТОПЛИВА И ВЫСОКОЭНЕРГЕТИЧЕСКИХ ВЕЩЕСТВ НА ОСНОВЕ СОЛЕЙ СУЛЬФАТИРОВАННЫХ АМИДОВ ОЛЕИНОВОЙ КИСЛОТЫ

\title{
ACID CORROSION INHIBITORS IN CHEMICAL TECHNOLOGY OF FUEL AND HIGH ENERGY SUBSTANCES BASED ON SALTS OF SULFATED OLEIC ACID AMIDES
}

\author{
Э.К. Аминова, В.В. Фомина, В.Н. Гайсина, А.В. Попова
}

Уфимский государственный нефтяной технический университет, филиал, г. Салават, Российская Федерация

Elmira K. Aminova, Vera V. Fomina, Veana N. Gaysina, Anastasiya V. Popova

Ufa State Petroleum Technological University, Branch, Salavat, Russian Federation e-mail: k.elmira.k@yandex.ru

Аннотация. В настоящее время разрушение металлического оборудования является одной из важнейших проблем в химической технологии топлива и высокоэнергетических веществ. Имеется потребность в новых более эффективных средствах борьбы с коррозией. Наиболее агрессивные среды распространены в нефтехимической промышленности (нефтяной, нефтегазовой, нефтеперерабатывающей и др.). Для защиты оборудования нефтепровода все больше используются азотсодержащие соединения, в частности аммонийные соли. Интерес представляют ингибиторы на основе органических соединений. 
Данная работа является продолжением серии исследований получения ингибиторов кислотной коррозии на основе карбоновых кислот. Разработана методика синтеза ингибиторов кислотной коррозии на основе амидов олеиновой кислоты. Причиной замедления коррозии является адсорбционная способность органических поверхностно-активных соединений (ПАВ). Это связано с перекрытием контактирующей поверхности металла со средой и изменением энергии активации на свободных участках. Основой разработанных ингибиторов является олеиновая кислота (ОК) - органическое жирное соединение, проявляющее свойства ПАВ. Известно, что содержание азота, серы и кислорода увеличивает защитную способность, поэтому для повышения ее ингибирующих свойств проведены несколько синтезов. Вещества были получены в несколько стадий. На первой стадии к ОК были добавлены аминоспирты, далее полученные соединения были сульфированы серной кислотой. Для расширения типов различных ингибиторов произведены реакции с основаниями. В результате образовались соли сульфатированных амидов олеиновой кислоты, синтезированной с аминоспитртами, серной кислоты и водных растворов оснований. Для определения эффективности полученных соединений проведена оценка защитной способности в разбавленной соляной кислоте. Установлено, что некоторые полученные вещества проявляют соответствующие свойства ингибиторов, при этом наиболее эффективным является аммонийная соль сульфатированного диэтаноламида олеиновой кислоты.

Abstract. At present, the destruction of metal equipment is one of the most important problems in the chemical technology of fuel and high-energy substances. There is a need for new, more effective corrosion control agents. The most aggressive environments are common in the petrochemical industry (oil, oil and gas, oil refining, etc.). To protect the equipment of the pipeline, nitrogen-containing compounds, in particular ammonium salts, are increasingly being used. Inhibitors based on organic compounds are of interest. 
This work is a continuation of studies series on the corrosion inhibitors preparation based on carboxylic acids. A method for the synthesis of acid corrosion inhibitors based on oleic acid amides has been developed. The reason for the slowdown in corrosion is the adsorption capacity of organic surfaceactive compounds (surfactants). This is due to the overlap of the contacting surface of the metal with the medium and a change in the activation energy in free areas. The basis of the developed inhibitors is oleic acid (OA) - an organic fatty compound that exhibits surfactant properties. It is known that the content of nitrogen, sulfur and oxygen increases the protective ability, therefore, several syntheses were carried out to increase its inhibitory properties. Substances were obtained in several stages. At the first stage, amino alcohols were added to OA, then the resulting compounds were sulfonated with sulfuric acid. To expand the types of various inhibitors, reactions with bases were carried out. As a result, salts of sulfated amides of oleic acid synthesized with amino alcohol, sulfuric acid, and aqueous solutions of bases were formed. To determine the effectiveness of the obtained compounds, the protective ability in dilute hydrochloric acid was evaluated. It was found that some of the obtained substances exhibit the corresponding properties of inhibitors. The most effective is the ammonium salt of sulfated diethanolamide oleic acid.

Ключевые слова: олеиновая кислота; ингибиторы коррозии; амиды; аминоспирты; кислотная коррозия; синтез

Key words: oleic acid; corrosion inhibitors; amides; amino alcohols; acid corrosion; synthesis

В настоящее время химическое и электрохимическое разрушения металлов являются одной из важнейших проблем при переработке нефти, поскольку уменьшают срок эксплуатации промышленного оборудования. Коррозия ведет к экономическим и экологическим потерям. Существует 
множество способов защиты металлов от коррозии. Одним из наиболее перспективных способов является применение ингибиторов коррозии.

Для защиты контактной поверхности металлоконструкций разумно изолировать металл от агрессивной среды. Наиболее подходящий способ это покрытие металла пленкой защитного характера. Поверхностноактивные вещества (ПАВ) проявляют адсорбционные свойства, которые способствуют образованию пленки на поверхности [1]. Гидрофильная природа металла затрудняет процесс вытеснения среды, поэтому ингибитор должен обладать достаточной защищающей и загущающей способностями, а также высоким уровнем нейтрализации агрессивного агента [2].

Цель настоящей работы - синтез ингибиторов кислотной коррозии на основе солей сульфатированных амидов олеиновой кислоты.

Молекула олеиновой кислоты обладает амфифильными свойствами, то есть длинная часть молекулы обладает гидрофобными свойствами, а компактная - гидрофильными. Именно такие молекулы проявляют поверхностную активность, также ингибирующая способность увеличивается в присутствии таких соединений, как азот, кислород и сера. Отличительной особенностью получения ингибиторов кислотной коррозии является применение аминов не только в виде свободных органических соединений, но и в виде солей $[3,4]$.

Сырьем для синтеза амидов олеиновой кислоты являются моноэтаноламин (МЭА), диэтаноламин (ДЭА) и техническая олеиновая кислота марки Б-115 в присутствии $20 \%$ раствора серной кислоты. Для получения солей сульфатированных амидов использовали следующее сырье: 20 \%-ый водный раствор серной кислоты; водные растворы едкого натрия, гидрокисда кальция и гидроксида аммония различной концентрации [5]. 
Проведена реакция этерификации олеиновой кислоты с моноэтаноламидом и диэтаноломамидом при мольном соотношении $1: 1$ в присутствии серной кислоты как катализатора.

Для последующего сульфирования в реакционную смесь добавляли $20 \%$-ый раствор серной кислоты при перемешивании при температуре 50-60 ${ }^{\circ} \mathrm{C}$ в течение 15 ч (по методике И.Т. Исмаилова [2]).

Для получения солей были использованы $10 \%$-ый, $20 \%$-ый, 40 \%-ый водные растворы $\mathrm{NaOH}, \mathrm{Ca}(\mathrm{OH})_{2}, \mathrm{NH}_{4} \mathrm{OH}$.

Реакцию проводили при комнатной температуре с перемешиванием в течение 15 мин.

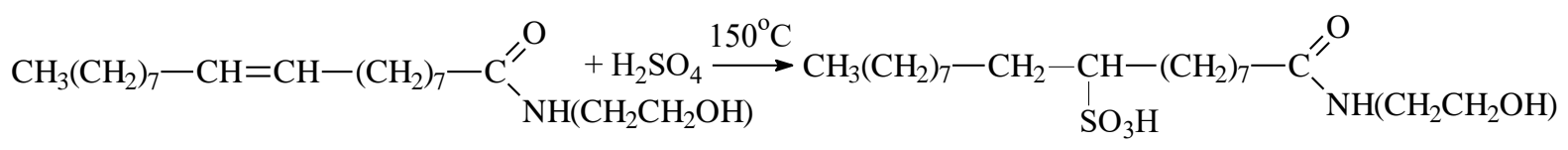

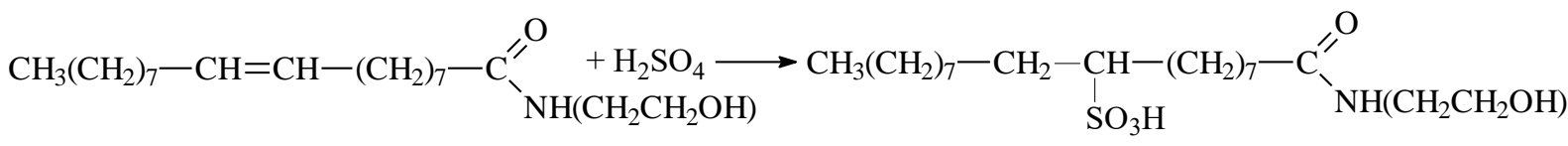

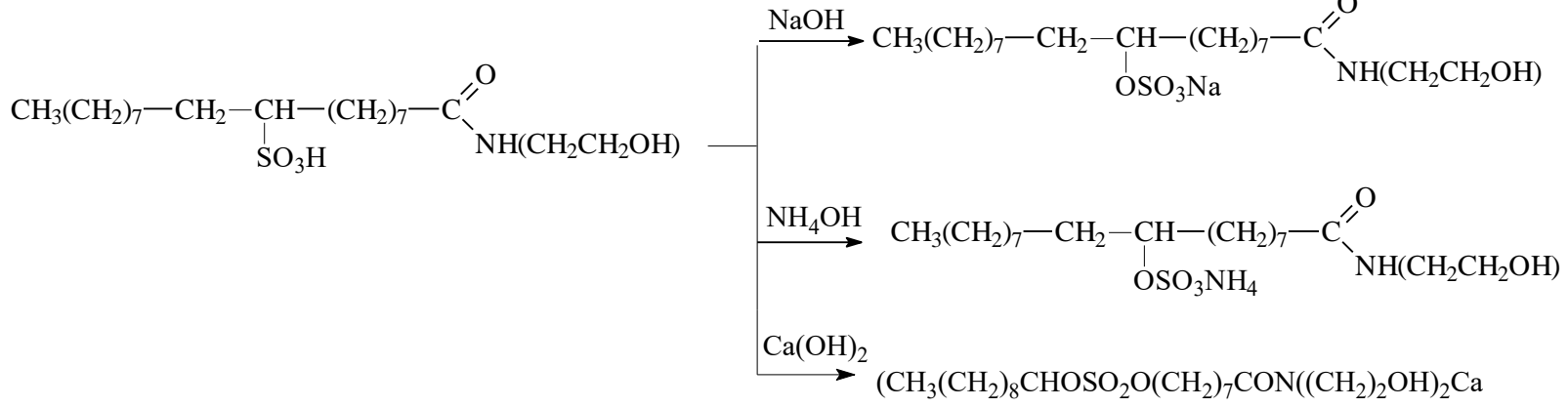

Для синтезированных солей было определено кислотное число по ГОСТ 31933-20122, которое подтвердило полное протекание реакции (таблица 1). 
Таблица 1. Кислотное число

\begin{tabular}{|l|c|c|}
\hline \multirow{2}{*}{ Соединение } & \multicolumn{2}{|c|}{ Кислотное число, мг } \\
\cline { 2 - 3 } & $\begin{array}{c}\text { До } \\
\text { этерификации }\end{array}$ & $\begin{array}{c}\text { После } \\
\text { этерификации }\end{array}$ \\
\hline $\mathrm{CH}_{3}\left(\mathrm{CH}_{2}\right)_{7} \mathrm{CH}=\mathrm{CH}\left(\mathrm{CH}_{2}\right)_{7} \mathrm{CONH}\left(\mathrm{CH}_{2}\right)_{2} \mathrm{OH}$ & 266,7 & - \\
\hline $\mathrm{CH}_{3}\left(\mathrm{CH}_{2}\right)_{7} \mathrm{CH}=\mathrm{CH}\left(\mathrm{CH}_{2}\right)_{7} \mathrm{CONH}\left(\mathrm{CH}_{2}\right)_{2} \mathrm{OH}$ & - & 69,4 \\
\hline $\mathrm{CH}_{3}\left(\mathrm{CH}_{2}\right)_{7} \mathrm{CH}=\mathrm{CH}\left(\mathrm{CH}_{2}\right)_{7} \mathrm{CON}\left(\left(\mathrm{CH}_{2}\right)_{2} \mathrm{OH}\right)_{2}$ & 226,6 & - \\
\hline $\mathrm{CH}_{3}\left(\mathrm{CH}_{2}\right)_{7} \mathrm{CH}=\mathrm{CH}\left(\mathrm{CH}_{2}\right)_{7} \mathrm{CON}\left(\left(\mathrm{CH}_{2}\right)_{2} \mathrm{OH}\right)_{2}$ & - & 64,8 \\
\hline
\end{tabular}

Выход полученных солей в зависимости от концентраций щелочных растворов представлен в таблице 2 .

Таблица 2. Выход солей при синтезе с водными растворами щелочами разной концентрации

\begin{tabular}{|c|c|c|c|}
\hline Исходные реагенты & Продукт & $\begin{array}{c}\text { Концентрации растворов } \\
\text { щелочей, \% }\end{array}$ & Выход, \% \\
\hline \multirow{3}{*}{ Соединение 6 и NaOH } & \multirow{3}{*}{ Соединение 8} & 10 & 86,1 \\
\hline & & 20 & 98,0 \\
\hline & & 30 & 98,5 \\
\hline \multirow{3}{*}{ Соединение 7 и $\mathrm{NaOH}$} & \multirow{3}{*}{ Соединение 9} & 10 & 87,3 \\
\hline & & 20 & 97,5 \\
\hline & & 30 & 97,0 \\
\hline \multirow{3}{*}{ Соединение 6 и $\mathrm{NH}_{4} \mathrm{OH}$} & \multirow{3}{*}{ Соединение 10} & 10 & 89,6 \\
\hline & & 20 & 97,8 \\
\hline & & 30 & 96,4 \\
\hline \multirow{3}{*}{ Соединение 7 и $\mathrm{NH}_{4} \mathrm{OH}$} & \multirow{3}{*}{ Соединение 11} & 10 & 85,7 \\
\hline & & 20 & 96,0 \\
\hline & & 30 & 95,8 \\
\hline \multirow{3}{*}{ Соединение 6 и $\mathrm{Ca}(\mathrm{OH})_{2}$} & \multirow{3}{*}{ Соединение 12} & 10 & 82,9 \\
\hline & & 20 & 93,7 \\
\hline & & 30 & 93,8 \\
\hline \multirow{3}{*}{ Соединение 7 и $\mathrm{Ca}(\mathrm{OH})_{2} 5$} & \multirow{3}{*}{ Соединение 13} & 10 & 83,8 \\
\hline & & 20 & 95,1 \\
\hline & & 30 & 96,2 \\
\hline
\end{tabular}


По результатам, приведенным в таблице 2, видно, что концентрация щелочи 10 \% недостаточна для практически полного выхода продуктов, а концентрация 30 \% нецелесообразна в использовании. Самый лучший выход показали соли, синтезированные на основе растворов щелочей с концентрацией $20 \%$.

Полученные соединения (соли, синтезированные на основе $20 \%$-ых растворов щелочей) также были проверены на защитное ингибирующее действие по ГОСТ 9.505-86 (таблица 3).

Таблица 3. Защитная эффективность солей сульфатированных амидов олеиновой кислоты

\begin{tabular}{|c|c|c|}
\hline № & Соединение & $\begin{array}{c}\text { Удельная потеря массы, } \\
\text { г/м }\end{array}$ \\
\hline 0 & $\mathrm{HCl} \mathrm{0,1} \mathrm{H}$ & 385,3 \\
\hline 1 & $\mathrm{CH}_{3}\left(\mathrm{CH}_{2}\right)_{8} \mathrm{CHOSO}_{2} \mathrm{ONa}\left(\mathrm{CH}_{2}\right)_{7} \mathrm{CONH}\left(\mathrm{CH}_{2}\right)_{2} \mathrm{OH}$ & 300,5 \\
\hline 2 & $\mathrm{CH}_{3}\left(\mathrm{CH}_{2}\right)_{8} \mathrm{CHOSO}_{2} \mathrm{ONH}_{4}\left(\mathrm{CH}_{2}\right)_{7} \mathrm{CONH}\left(\mathrm{CH}_{2}\right)_{2} \mathrm{OH}$ & 133,3 \\
\hline 3 & $\left(\mathrm{CH}_{3}\left(\mathrm{CH}_{2}\right)_{8} \mathrm{CHOSO}_{2} \mathrm{O}^{-2}\left(\mathrm{CH}_{2}\right)_{7} \mathrm{CONH}\left(\mathrm{CH}_{2}\right)_{2} \mathrm{OH}\right)_{2} \mathrm{Ca}$ & 260,5 \\
\hline 4 & $\mathrm{CH}_{3}\left(\mathrm{CH}_{2}\right)_{8} \mathrm{CHOSO}_{2} \mathrm{ONa}\left(\mathrm{CH}_{2}\right)_{7} \mathrm{CON}\left(\left(\mathrm{CH}_{2}\right)_{2} \mathrm{OH}\right)_{2}$ & 285,4 \\
\hline 5 & $\mathrm{CH}_{3}\left(\mathrm{CH}_{2}\right)_{8} \mathrm{CHOSO}_{2} \mathrm{ONH}_{4}\left(\mathrm{CH}_{2}\right)_{7} \mathrm{CON}\left(\left(\mathrm{CH}_{2}\right)_{2} \mathrm{OH}\right)_{2}$ & 58,9 \\
\hline 6 & $\left(\mathrm{CH}_{3}\left(\mathrm{CH}_{2}\right)_{8} \mathrm{CHOSO}_{2} \mathrm{O}^{-2}\left(\mathrm{CH}_{2}\right)_{7} \mathrm{CON}\left(\left(\mathrm{CH}_{2}\right)_{2} \mathrm{OH}\right)_{2}\right)_{2} \mathrm{Ca}$ & 80,6 \\
\hline 7 & уротропин & 45,2 \\
\hline
\end{tabular}

\section{Выводы}

1. В результате испытаний на защитное ингибирующее действие синтезированных реагентов установлено, что сульфатированный диэтаноламид олеиновой кислоты проявляет антикоррозионные свойства лучше, чем сульфатированный моноэтаноламид олеиновой кислоты.

2. Максимальный ингибиторный эффект проявила аммонийная соль сульфатированного диэтаноламида олеиновой кислоты, что является обоснованием выгодного использования ее в целях защиты оборудования от коррозии. 


\section{Список используемых источников}

1. Козлова Л.С., Сибилева С.В., Чесноков Д.В., Кутырев А.Е. Ингибиторы коррозии (обзор) // Авиационные материалы и технологии. 2015. № 2 (35). C. 67-75.

2. Уварова Н.Н. Амиды высших карбоновых кислот как полифункциональна добавка к минеральному маслу И-20А // Вестник ТГУ. 1997. Т. 2. Вып. 1. С. 70-75.

3. Исмаилов И.Т. Синтез и поверхностноактивные свойства солей сульфатированных амидов на основе олеиновой кислоты и этаноламидов // Kimya Problemleri. 2015. № 2. C. 144-153.

4. Загидуллин Р.Н., Дмитриева Т.Г., Загидуллин С.Н., Идрисова В.А. Разработка процесса получения новых ингибиторов кислотной коррозии // Башкирский химический журнал. 2012. Т. 19. № 2. С. 31-35.

5. Аминова Э.К., Фомина В.В., Лихачева Н.А., Гайсина В.Н., Попова А.В. Синтез ингибиторов кислотной коррозии на основе олеиновой кислоты и аминоспиртов // Сетевое издание «Нефтегазовое дело». 2019. № 3. C. 116-125. URL: http://ogbus.ru/files/ogbus/issues/3_2019/ogbus_3_ 2019_p116-125.pdf (дата обращения: 20.11.2019). DOI: 10.17122/ogbus2019-3-116-125.

\section{References}

1. Kozlova L.S., Sibileva S.V., Chesnokov D.V., Kutyrev A.E. Ingibitory korrozii (obzor) [Corrosion Inhibitors (Review)]. Aviatsionnye materialy $i$ tekhnologii - Aviacionnye Materialy and Tehnologii, 2015, No. 2 (35), pp. 67-75. [in Russian].

2. Uvarova N.N. Amidy vysshikh karbonovykh kislot kak polifunktsional'na dobavka k mineral'nomu maslu I-20A [Amides of Higher Carboxylic Acids as a Multifunctional Additive to I-20A Mineral Oil]. Vestnik TGU - Tomsk State University Journal, 1997, Vol. 2, Issue 1, pp. 70-75. [in Russian]. 
3. Ismailov I.T. Sintez i poverkhnostnoaktivnye svoistva solei sul'fatirovannykh amidov na osnove oleinovoi kisloty i etanolamidov [Synthesis and Surface-Active Properties of Salts of Sulphated Amides on the Basis of Oleic Acid and Ethanolamins]. Kimya Problemleri - Chemical Problems, 2015, No. 2, pp. 144-153. [in Russian].

4. Zagidullin R.N., Dmitrieva T.G., Zagidullin S.N., Idrisova V.A. Razrabotka protsessa polucheniya novykh ingibitorov kislotnoi korrozii [The Development Process of Obtaining of New Inhibitors of Acid Corrosion]. Bashkirskii khimicheskii zhurnal - Bashkir Chemical Journal, 2012, Vol. 19, No. 2, pp. 31-35. [in Russian].

5. Aminova E.K., Fomina V.V., Likhacheva N.A., Gaisina V.N., Popova A.V. Sintez ingibitorov kislotnoi korrozii na osnove oleinovoi kisloty i aminospirtov [Acid Corrosion Inhibitors Synthesis on the Basis of Oleic Acid and Amino Alcohol]. Setevoe izdanie «Neftegazovoe delo» - Online Edition «Oil and Gas Business», 2019, No. 3, pp. 116-125. URL: http://ogbus.ru/ files/ogbus/issues/3_2019/ogbus_3_2019_p116-125.pdf (accessed 20.11.2019). DOI: 10.17122/ogbus-2019-3-116-125. [in Russian].

\section{Сведения об авторах}

\section{About the authors}

Аминова Эльмира Курбанаглиевна, канд. хим. наук, доцент кафедры «Химико-технологические процессы», УГНТУ, филиал, г. Салават, Российская Федерация

Elmira K. Aminova, Candidate of Chemical Sciences, Assistant Professor of Chemical and Technological Processes Department, USPTU, Branch, Salavat, Russian Federation

e-mail: k.elmira.k@yandex.ru 
Фомина Вера Васильевна, канд. техн. наук, доцент кафедры «Химикотехнологические процессы», УГНТУ, филиал, г. Салават, Российская Федерация

Vera V. Fomina, Candidate of Engineering Sciences, Assistant Professor of Chemical and Technological Processes Department, USPTU, Branch, Salavat, Russian Federation.

e-mail: asterhtp@mail.ru

Гайсина Веана Ниязовна, студент кафедры «Химико-технологические процессы», УГНТУ, филиал, г. Салават, Российская Федерация

Veana N. Gaysina, Student of Chemical and Technological Processes Department, USPTU, Branch, Salavat, Russian Federation

Попова Анастасия Владимировна, студент кафедры «Химикотехнологические процессы», УГНТУ, филиал, г. Салават, Российская Федерация

Anastasiya V. Popova, Student of Chemical and Technological Processes Department, USPTU, Branch, Salavat, Russian Federation 